\title{
BMJ Open A UK clinical audit addressing the quality of prescribing of sodium valproate for bipolar disorder in women of childbearing age
}

\author{
Carol Paton, ${ }^{1,2}$ John Cookson, ${ }^{3}$ I Nicol Ferrier, ${ }^{4}$ Sumera Bhatti, ${ }^{1}$ Elizabeth Fagan, ${ }^{1}$ \\ Thomas R E Barnes ${ }^{1,2}$
}

To cite: Paton C, Cookson J, Ferrier IN, et al. A UK clinical audit addressing the quality of prescribing of sodium valproate for bipolar disorder in women of childbearing age. BMJ Open 2018;8:e020450. doi:10.1136/ bmjopen-2017-020450

- Prepublication history for this paper is available online. To view these files, please visit the journal online (http://dx.doi. org/10.1136/bmjopen-2017020450).

Received 9 November 2017 Revised 16 February 2018 Accepted 5 March 2018

Check for updates

${ }^{1}$ Prescribing Observatory for Mental Health (POMH-UK), Royal College of Psychiatrists, London, UK

${ }^{2}$ The Centre for Psychiatry, Imperial College London, London, UK

${ }^{3}$ Tower Hamlets Centre for Mental Health, Royal London Hospital, London, UK

${ }^{4}$ Institute of Neuroscience,

Newcastle University, Newcastle, UK

Correspondence to

Carol Paton;

carol.paton@nhs.net

\section{ABSTRACT}

Objectives To review prescribing practice concerning valproate, an established human teratogen, for the management of bipolar disorder in women of childbearing age.

Design The Prescribing Observatory for Mental Health conducted a baseline clinical audit in the UK, as part of a quality improvement programme.

Participants Six hundred and forty-eight clinical teams from 55 mental health Trusts submitted retrospective treatment data relating to patients with a diagnosis of bipolar disorder.

Results Of the audit sample of 6705 patients, 3854 were 50 years of age or younger. Valproate was prescribed for $24 \%$ of women and $43 \%$ men in this age group, and the mean dose of valproate was lower in women $(1196 \mathrm{mg})$ than in men $(1391 \mathrm{mg})$. For only half of such women was there documented evidence that information had been provided on the risks for the unborn child and the need for adequate contraception. Valproate was more often used in men to treat mania and aggression, while the most common treatment targets in women were hypomania and relapse prevention.

Conclusions Despite explicit recommendations in national treatment guidelines and published safety alerts and warnings regarding the use of valproate in women of childbearing age, current prescribing of this medication to such women in the context of the treatment of bipolar disorder falls short of best practice, particularly with regard to provision of information regarding the risks associated with exposure to valproate during pregnancy. While women younger than 50 years of age were less likely to be prescribed valproate than men in the same age group, and at a lower dosage, it is unclear to what extent this reflects clinicians' concerns about teratogenicity or is driven by perceptions of the indication for valproate, and the dosage required, for the treatment of different phases of the disorder in men and women.

\section{INTRODUCTION}

Valproate is recommended by the National Institute for Health and Care Excellence (NICE) as a second-line treatment for the prevention of relapse in bipolar disorder. ${ }^{1}$
Strengths and limitations of this study

- Clinical performance was assessed against practice standards that were derived from evidence-based national treatment guidelines.

- The generalisability of the audit findings rests on the large national sample size, with data submitted by the vast majority of English NHS mental health Trusts.

- Each participating mental health service was invited to submit prescribing data on a random sample of eligible patients on their caseload, so any systematic sampling bias is unlikely.

- The findings regarding valproate prescribing are based on self-report data from secondary care mental health services, and relate only to measures and assessments that were documented in the clinical records.

- The findings may not be extrapolated beyond secondary mental health services.

There is also some evidence for efficacy in the treatment of mania ${ }^{23}$ and bipolar depression. ${ }^{4}$

The teratogenic potential of valproate, first identified over 30 years ago, ${ }^{5}$ is dose-related. $^{6} 7$ Major congenital malformations (MCMs), defined as structural abnormalities of surgical, medical, functional or cosmetic importance, have been reported in over $9 \%$ of children exposed to valproate in utero, with neural tube defects, cardiac malformations, cleft palate and lip, and hypospadias each occurring in $1 \%-2 \%$ of live births. ${ }^{8}$ In addition, exposure to valproate in utero has been found to reduce IQ by an average of 9 points ${ }^{9}$ and increase the risk of developing childhood autism fivefold. ${ }^{10}$ However, it may not be valid to directly extrapolate these data, derived largely from women with epilepsy treated with valproate to pregnant women with bipolar disorder receiving the drug. ${ }^{11}$ Nevertheless, this evidence led the European Medicines Agency pharmacovigilance and 
risk assessment committee to strengthen existing recommendations that valproate should not be used to treat epilepsy or bipolar disorder in women who are pregnant or who can become pregnant unless other treatments have proved ineffective or intolerable. ${ }^{12}$ In 2017, the French National Agency for the Safety of Medicines and Health Products announced a ban on the use of valproate for women with a diagnosis of bipolar disorder who were either pregnant or of childbearing age with no efficient contraception. ${ }^{13}$

Despite clear recommendations to avoid prescribing valproate for women of childbearing age, ${ }^{14}$ several small-scale audits in UK services have reported that clinical practice in this area is suboptimal. ${ }^{15-18}$ In 2016, the Prescribing Observatory for Mental Health (POMH-UK) embarked on a quality improvement programme (QIP) focusing on the use of valproate in people with bipolar disorder and conducted a baseline clinical audit. One focus of the QIP was the use of valproate in women of childbearing age, for whom such treatment should generally be avoided, only to be prescribed if the appropriate safeguards have been put in place. For the purposes of the clinical audit, the assumption was made that women who were 50 years of age or younger could potentially conceive, and so we report here on prescribing practice for the subsamples of women and men in this age category in the national sample.

\section{METHOD}

POMH-UK invited all member healthcare organisations (most of which are NHS mental health Trusts) to participate in an audit-based QIP focusing on the use of valproate in people with a diagnosis of bipolar disorder. All Trusts and clinical teams were self-selected in that they chose to participate.

Selected clinical practice standards for the audit, derived from the NICE guideline for bipolar disorder (NICE 2014) were as follows:

1. Valproate should not be used routinely for women of childbearing age.

2. Where valproate is prescribed for a woman of childbearing age, there should be documented evidence that the woman

a. is aware of the need to use adequate contraception

b. has been informed of the risks that valproate would pose to an unborn baby.

Trusts were asked to identify a sample of patients with a clinical or ICD-10 coded diagnosis of bipolar disorder. The following data were collected on each eligible patient, using a bespoke data collection tool: age, gender, ethnicity, nature of the clinical service providing care, current phase of bipolar disorder, whether the bipolar disorder was rapid cycling, any other ICD-10 psychiatric diagnoses, whether valproate was prescribed or not and, if so, the dose prescribed. For those patients who had started treatment with valproate in the previous 6 months, the clinical indications/reasons for prescribing were collected. With respect to women of childbearing age (defined pragmatically as being 50 years of age or younger), data were also collected in this same subsample relating to documentation of a discussion informing the woman of the teratogenic potential of valproate, the need for adequate contraception and whether contraception was known to be in place.

Clinicians and clinical audit staff in each Trust collected the audit data; ethical approval is not required for auditbased quality improvement initiatives. Anonymised data were submitted online using Formic software (http:// www.Formic.com/survey-software/) and stored and analysed using SPSS V.21.

\section{Data analysis}

Analysis of data was performed using SPSS V.21 ${ }^{19}$. The demographic and clinical characteristics of men and women in the total national sample who were 50 years of age or younger were analysed using simple descriptive statistics.

Binary logistic regression analyses were used to explore demographic and clinical variables associated with the prescription of valproate. In a series of univariable analyses, being prescribed valproate (yes or no) was the dependent variable, with ethnicity, age, gender, the clinical service providing care, the current phase of bipolar disorder, whether the illness was rapid cycling, other current psychiatric diagnoses and whether bipolar illness was the sole diagnosis or another diagnosis coexisted were the independent variables. The association of these variables with the prescription of valproate was then examined in a multivariable analysis using a backwards selection procedure until only the statistically significant variables remained.

An independent samples t-test was used to compare the dose of valproate prescribed for women aged 50 years or younger with that prescribed for men in the same age group.

\section{RESULTS}

A total of 648 clinical teams from 55 mental health provider organisations participated in this baseline audit. The data collection tool was completed for 6705 patients with bipolar disorder, 2416 (36\%) of whom were prescribed valproate.

\section{Prevalence of valproate use in women of childbearing age}

In the total national sample, $2364(35 \%)$ were women of 50 years of age or younger and $1490(22 \%)$ were men in the same age category; the demographic and clinical characteristics of these two subgroups are shown in table 1. Of the 2364 women, $574(24 \%)$ were prescribed valproate. The respective figures for the 1490 men were 648 (43\%).

\section{Valproate dose}

The doses of valproate prescribed for the subsamples of women and men who were 50 years of age or younger 
Table 1 Key demographic and clinical characteristics of the subsamples of men and women 50 years of age or younger

\begin{tabular}{|c|c|c|}
\hline $\begin{array}{l}\text { Key demographic and } \\
\text { clinical characteristics }\end{array}$ & $\begin{array}{l}\text { Women } 50 \text { years } \\
\text { of age or younger } \\
(n=2364) N(\%)\end{array}$ & $\begin{array}{l}\text { Men } 50 \text { years of } \\
\text { age or younger } \\
(n=1490) N(\%)\end{array}$ \\
\hline \multicolumn{3}{|l|}{ Ethnicity } \\
\hline White/white British & $1733(73)$ & $1067(72)$ \\
\hline Asian/Asian British & $184(8)$ & $143(10)$ \\
\hline Black/black British & $171(7)$ & $125(8)$ \\
\hline Mixed or other & $135(6)$ & $74(5)$ \\
\hline $\begin{array}{l}\text { Not stated/refused/not } \\
\text { collected }\end{array}$ & $141(6)$ & $81(5)$ \\
\hline \multicolumn{3}{|l|}{ Age bands } \\
\hline Younger than 20 years & $17(<1)$ & $16(1)$ \\
\hline 21-30years & $403(17)$ & $273(18)$ \\
\hline $31-40$ years & $772(33)$ & $471(32)$ \\
\hline $41-50$ years & $1172(50)$ & $730(49)$ \\
\hline \multicolumn{3}{|l|}{ Clinical service providing care } \\
\hline $\begin{array}{l}\text { Adult community mental } \\
\text { health team }\end{array}$ & $2113(89)$ & $1243(83)$ \\
\hline $\begin{array}{l}\text { Acute adult psychiatric } \\
\text { ward or psychiatric } \\
\text { intensive care ward }\end{array}$ & $161(7)$ & $142(9)$ \\
\hline $\begin{array}{l}\text { Adult home treatment } \\
\text { team/crisis team }\end{array}$ & $50(2)$ & $23(2)$ \\
\hline $\begin{array}{l}\text { Adult inpatient } \\
\text { rehabilitation services }\end{array}$ & $12(<1)$ & $12(1)$ \\
\hline Forensic services & $20(<1)$ & $67(4)$ \\
\hline $\begin{array}{l}\text { Tertiary affective } \\
\text { disorders service }\end{array}$ & $8(<1)$ & $3(<1)$ \\
\hline \multicolumn{3}{|c|}{ Current phase of bipolar disorder (ICD-10 codes) } \\
\hline Manic (F31.1, F31.2) & $184(8)$ & $155(10)$ \\
\hline Hypomanic (F31.0) & $144(6)$ & $106(7)$ \\
\hline Mixed (F31.6) & $138(6)$ & $53(4)$ \\
\hline $\begin{array}{l}\text { Depressed (F31.3, } \\
\text { F31.4, F31.5) }\end{array}$ & $329(14)$ & $161(11)$ \\
\hline $\begin{array}{l}\text { Stable in partial or full } \\
\text { remission }\end{array}$ & $1231(52)$ & $799(54)$ \\
\hline Unclear or other & $338(14)$ & $216(14)$ \\
\hline \multicolumn{3}{|l|}{ Rapid cycling illness } \\
\hline Yes & $82(3)$ & $42(3)$ \\
\hline No & $2282(97)$ & $1448(97)$ \\
\hline \multicolumn{3}{|c|}{ Other current psychiatric diagnoses* within ICD10 F categories } \\
\hline F00-F09 & $10(<1)$ & $7(<1)$ \\
\hline F10-F19 & $194(8)$ & $306(21)$ \\
\hline F20-F29 & $87(4)$ & $85(6)$ \\
\hline $\begin{array}{l}\text { F30, F32-39 excluding } \\
\text { bipolar disorder }\end{array}$ & $76(3)$ & $32(2)$ \\
\hline F40-F48 & $160(7)$ & $64(4)$ \\
\hline F50-F59 & $38(2)$ & $6(<1)$ \\
\hline F60-F69 & $302(13)$ & $114(8)$ \\
\hline $\mathrm{F} 70-\mathrm{F} 79$ & $14(<1)$ & 24 (2) \\
\hline
\end{tabular}

Continued
Table 1 Continued

\begin{tabular}{ccc}
\hline $\begin{array}{l}\text { Key demographic and } \\
\text { clinical characteristics }\end{array}$ & $\begin{array}{l}\text { Women 50years } \\
\text { of age or younger } \\
(\mathbf{n}=\mathbf{2 3 6 4 )} \mathbf{N}(\%)\end{array}$ & $\begin{array}{l}\text { Men 50years of } \\
\text { age or younger } \\
(\mathbf{n}=\mathbf{1 4 9 0 )} \mathbf{N}(\%)\end{array}$ \\
\hline F80-F89 & $17(<1)$ & $32(2)$ \\
\hline F90-F98 & $15(<1)$ & $24(2)$ \\
\hline F99 & $10(<1)$ & $9(<1)$ \\
\hline None & $1543(65)$ & $887(60)$ \\
\hline Not known & $45(2)$ & $26(2)$ \\
\hline Number of current psychiatric diagnoses & $913(61)$ \\
\hline Bipolar disorder only & $1588(67)$ & $463(31)$ \\
\hline One other & $653(27)$ & $114(8)$ \\
\hline Multiple & $123(5)$ & \\
\hline
\end{tabular}

*ICD-10 codes and diagnoses: F00-F09-organic, including symptomatic, mental disorders; F10-F19-mental and behavioural disorders due to psychoactive substance use; F20-F29schizophrenia, schizotypal and delusional disorders; F30-F39mood (affective) disorders; F40-F48-neurotic, stress-related and somatoform disorders; F50-F59-behavioural syndromes associated with physiological disturbances and physical factors; F60-F69-disorders of adult personality and behaviour; F80-F89disorders of psychological development; F90-F98-behavioural and emotional disorders with onset occurring in childhood and adolescence; F99-unspecified mental disorder.

are shown in table 2 . The mean daily dose of valproate prescribed for such women $(1196 \mathrm{mg})$ was significantly lower than the mean daily dose prescribed for men $(1391 \mathrm{mg}) ; \mathrm{t}=6.227, \mathrm{df}=1217, \mathrm{p}<0.001$.

\section{Factors associated with the prescription of valproate}

The multivariable analysis revealed that age, gender, the clinical service providing care, the current phase of bipolar disorder, a rapid-cycling illness and a diagnosis of a comorbid substance misuse or anxiety disorder were all associated with the prescription of valproate. The direction and strength of these associations are shown in table 3 .

\section{Clinical reasons for prescribing valproate}

Treatment with valproate had been initiated in the previous 6 months in 162 patients ( 74 women and 88 men) aged 50 years or younger. Figure 1 shows the clinical rationales for prescribing valproate for each gender in this subsample. Hypomanic symptoms and relapse prevention were more common clinical reasons for prescribing valproate in women, while manic symptoms and aggressive behaviour were more common reasons in men.

\section{Informing women of the teratogenic risk of valproate and protection against pregnancy}

In the 74 women who were 50 years of age or younger and had started valproate treatment in the last 6 months, there was documented evidence that $37(50 \%)$ had been informed of the risks to the fetus (including neural tube defects) and that $18(24 \%)$ had been informed of the implications for the longer term neurodevelopment of 
Table 2 Prescribed daily dose of valproate in the subsamples of women and men 50 years of age or younger, and reported prevalence figures for major congenital malformations (MCM) associated with prenatal exposure to these doses as reported from the UK and Ireland epilepsy and pregnancy registers

\begin{tabular}{|c|c|c|c|}
\hline \multirow[b]{2}{*}{ Daily valproate dose } & \multicolumn{2}{|c|}{ Subsamples 50 years of age or younger } & \multirow{2}{*}{$\begin{array}{l}\text { Prevalence of MCM at each dosage range } \\
\text { identified in the UK and Ireland registers }{ }^{7}(\%)\end{array}$} \\
\hline & Women $(n=574)$ & Men $(n=648)$ & \\
\hline$\leq 600 \mathrm{mg}$ & 77 & 65 & 5.1 \\
\hline$>1000 \mathrm{mg}$ & 277 & 383 & 10.4 \\
\hline
\end{tabular}

the child (such as neurodevelopmental delay and autistic spectrum disorders). The need for adequate contraception had been discussed with $41(55 \%)$ of these women, nine $(12 \%)$ of whom were prescribed an oral contraceptive, four $(5 \%)$ had an IUD in place, six $(8 \%)$ had received an injectable contraceptive or implant and six $(8 \%)$ were using another method of contraception. There was no documented protection against pregnancy in 49 (65\%).

\section{DISCUSSION}

Prevalence of valproate use in women of childbearing age and clinical reasons for use

The prevalence of valproate prescribing in women of childbearing age ( 50 years of age or younger) who had a diagnosis of bipolar disorder was just over half that found in men in the same age group. Where valproate was prescribed for such women, compared with men in the same age group, the target symptoms were less likely to be those associated with mania. One possible explanation for these findings is that clinicians are aware of the teratogenic potential of valproate and avoid the use of this medicine where possible, particularly in women who may be particularly vulnerable to having an unplanned pregnancy, such as during an episode of hypomania or mania. However, the differences observed in the frequency of valproate use for women and men under 50 years of age may also reflect clinicians' perceptions of the effectiveness of valproate in each phase of the disorder.

\section{Valproate dose}

The association between valproate and congenital malformations is clearly dose-related in the treatment of epilepsy; analysis of data from just over a thousand valproate-exposed pregnancies on the EURAP registry (European Registry of Antiepileptic Drugs and Pregnancy) revealed that the rate of congenital malformations identified by 1 year of age was $5.6 \%$ when the daily dose of valproate was less than $700 \mathrm{mg}$ at conception, $10.4 \%$ when the dose was between 700 and $1499 \mathrm{mg}$, and $24.2 \%$ when the dose was $1500 \mathrm{mg}$ or higher. ${ }^{6}$ A further prospective observational study of 1220 women exposed to valproate monotherapy during pregnancy reported an MCM prevalence of $5 \%$ by 6 weeks of age with a daily dose of $600 \mathrm{mg}$ or less, $6.1 \%$ with a daily dose of $600-1000 \mathrm{mg}$ and $10.4 \%$ with a daily dose higher than $1000 \mathrm{mg}^{7}$ The Medicines and Healthcare products Regulatory Agency ${ }^{18}$ has concluded that while the teratogenic potential of valproate is greatest at higher doses, which they define as being above $1000 \mathrm{mg}$ daily, the available data do not allow for the identification of a threshold dose of valproate, below which there is no teratogenic risk.

Table 3 Logistic regression model for factors associated with the prescription of valproate

\begin{tabular}{|c|c|c|}
\hline Variable & OR $(95 \% \mathrm{CI})$ & $P$ values \\
\hline Age (years) & & $<0.001$ \\
\hline $16-25$ & 1 & \\
\hline $26-35$ & $1.11(0.82$ to 1.48$)$ & \\
\hline $36-45$ & 1.47 (1.11 to 1.95$)$ & \\
\hline $46-50$ & 1.64 (1.22 to 2.19$)$ & \\
\hline Gender & & $<0.001$ \\
\hline Female & 1 & \\
\hline Male & 2.23 (1.91 to 2.59$)$ & \\
\hline Clinical service & & 0.004 \\
\hline Adult community & 1 & \\
\hline Acute adult ward/PICU & $1.38(1.03$ to 1.85$)$ & \\
\hline $\begin{array}{l}\text { Tertiary affective disorders } \\
\text { service }\end{array}$ & 1.67 (0.48 to 5.87$)$ & \\
\hline Inpatient rehabilitation & 1.24 (0.49 to 3.18$)$ & \\
\hline Forensic service & 2.51 (1.47 to 4.26$)$ & \\
\hline $\begin{array}{l}\text { Home treatment/crisis } \\
\text { team }\end{array}$ & $0.79(0.45$ to 1.39$)$ & \\
\hline \multicolumn{2}{|c|}{ Current phase of bipolar disorder } & $<0.001$ \\
\hline Stable & 1 & \\
\hline Hypomania & $1.20(0.90$ to 1.60$)$ & \\
\hline Mixed affective state & $1.13(0.81$ to 1.57$)$ & \\
\hline Mania & 1.53 (1.17 to 2.01$)$ & \\
\hline Depressed & 0.79 (0.63 to 0.99$)$ & \\
\hline Other & 0.64 (0.46 to 0.91$)$ & \\
\hline Rapid cycling illness & & 0.02 \\
\hline No & 1 & \\
\hline Yes & $1.62(1.10$ to 2.41$)$ & \\
\hline \multicolumn{2}{|c|}{ Comorbid substance misuse (F10-19) } & 0.007 \\
\hline No & 1 & \\
\hline Yes & 1.34 (1.08 to 1.66$)$ & \\
\hline \multicolumn{2}{|c|}{ Comorbid anxiety spectrum disorder (F40-48) } & 0.02 \\
\hline No & 1 & \\
\hline Yes & 0.65 (0.45 to 0.92$)$ & \\
\hline
\end{tabular}

ICD, International Classification of Diseases; IUD, intra-uterine device; PICU, Psychiatric Intensive Care Unit. 


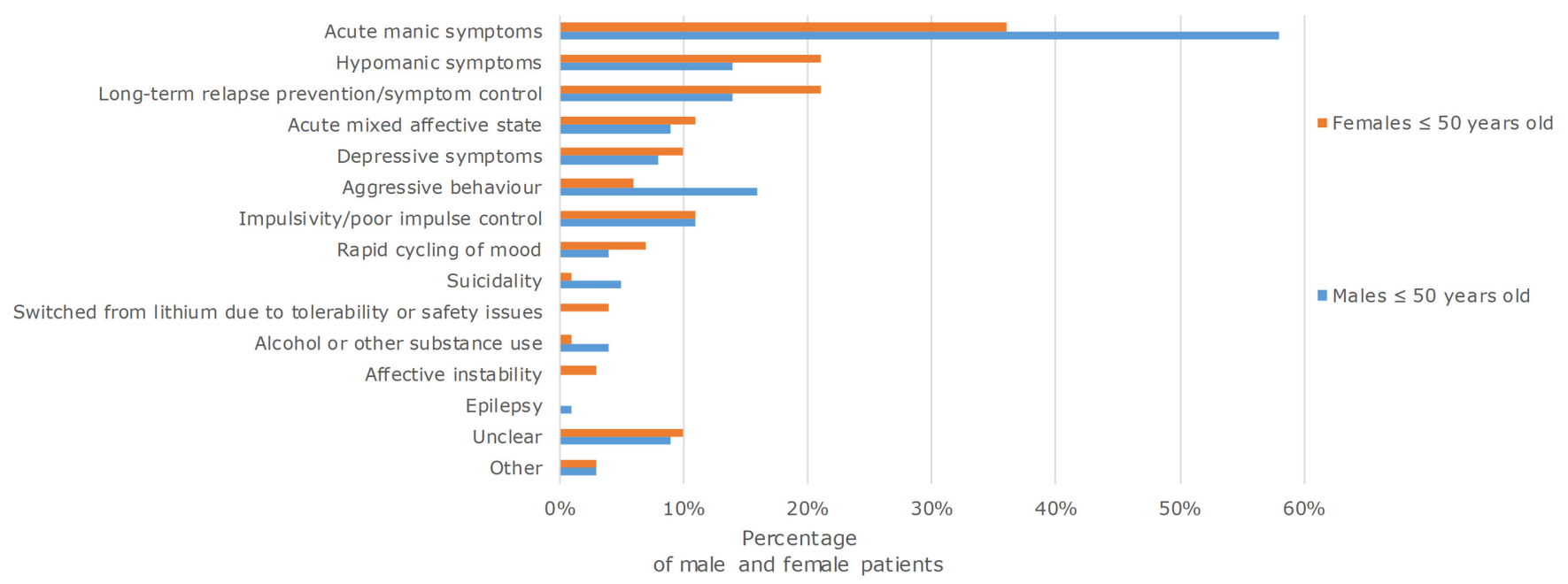

Figure 1 Clinical reasons/target symptoms for starting valproate treatment in a subsample of women $(n=74)$ and men $(n=88)$ with a diagnosis of bipolar disorder, 50 years of age or younger.

Our data revealed that while the women in our national sample were prescribed a lower average dose of valproate than men, $90 \%$ of the women of childbearing age were prescribed a daily dose of valproate of more than $600 \mathrm{mg}$, and more than half a daily dose of more than $1000 \mathrm{mg}$. This latter proportion was similar to that found in systematic audits conducted 10 years ago in South-East London ${ }^{15}$ and Manchester, ${ }^{16}$ and suggests that the dose of valproate prescribed for such women is not noticeably decreasing. Further, it remains unclear whether the lower doses used for women under 50 years of age reflect concern about the potential teratogenic effects, the different phases of the disorder being treated in men and women or a general principle of prescribing lower dosages for women because of their poorer tolerability of medication.

\section{Informing women of the teratogenic risk of valproate and the need to protect against pregnancy}

Of the women of childbearing age in our national sample, there was documented evidence that half of those who started treatment with valproate had been informed of the teratogenic potential of this medicine. This is double the proportion of women reported to have received this information in the local clinical audits by James $e t a l^{15}$ and Wieck et $a l^{16}$ mentioned above, and a third higher than that found in another, more recent audit in the UK. ${ }^{18}$ When considered together, there is some evidence from these independent clinical audits that practice with respect to informing women about the risks associated with valproate treatment is improving over time, but absolute adherence to our clinical practice standard remains disappointing given the high profile warnings from NICE, ${ }^{1}$ the $\mathrm{EMA}^{12}$ and, jointly, the MHRA and NHS Improvement. ${ }^{20}$ A QIP conducted within South London and Maudsley NHS Foundation Trust between 2008 and 2009 reported a sixfold increase in the proportion of women informed about the teratogenic potential of valproate from one in ten to almost two-thirds. ${ }^{17}$ However, the intervention used to achieve this improvement was resource intensive: it comprised a systematic second check of the clinical records of women starting valproate treatment, and where there was no documentation that the required information had been given, a personalised prompt to the prescriber and the option of a clinical pharmacist speaking with the female patient should the prescriber be unable to. Such a demanding intervention, which still managed to miss one woman in three, would be unlikely to be sustainable in the medium to long term.

We found that there was documented evidence that contraception had been discussed for just over half the women of childbearing age who recently started treatment with valproate. This proportion is higher than noted in the previous local audits ${ }^{15}$ and is consistent with the modest improvements seen over time in the proportion of women informed about the teratogenic potential of valproate.

\section{CONCLUSION}

Despite explicit recommendations in evidence-based, national treatment guidelines as well as widely disseminated safety alerts and warnings regarding the use of valproate in women of childbearing age, current prescribing of this medication to women in this age group with a diagnosis of bipolar disorder falls short of best practice, particularly with regard to the provision of information regarding the risks to the unborn child associated with exposure to valproate during pregnancy. We found that women of childbearing age were less likely to be prescribed valproate than men, and that when valproate was prescribed for such women, the dose was lower than that used in men. However, it is unclear to what extent these differences in prescribing practice 
reflect concerns about teratogenicity. An alternative explanation, suggested by our data, is that valproate is more often prescribed in men to treat mania or aggression, and it is possible that clinicians perceive that such indications warrant higher doses than those needed to treat the most common indications in younger women, which were hypomania or the prevention of relapse.

Acknowledgements Acknowledgements are due to the clinicians and other staff in participating services who collected and submitted the audit data. Thanks are also due to members of the POMH-UK team aside from the coauthors of this paper: Krysia Zalewska, Suzie Lemmey.

Contributors CP, TREB, JC, INF, SB and EF contributed to the conception or design of the data collection tool, and the acquisition, analysis and interpretation of data for the work. The paper was written by CP and TREB, and JC and INF revised it critically for important intellectual content. All six authors approved the final version submitted for publication and agreed to be accountable for the accuracy or integrity of any part of the work.

Funding POMH-UK was originally funded by a tapering grant from an independent charity, the Health Foundation, under its 'Engaging with Quality' initiative. It is now funded entirely from the subscriptions of member mental health services, principally mental health NHS Trusts.

Competing interests In the past 3 years, TREB has received speaker fees from Janssen and been a member of scientific advisory boards for Sunovion, Otsuka/ Lundbeck and Newron Pharmaceuticals. CP has undertaken consultancy work for Eli-Lilly.

\section{Patient consent Not required.}

Provenance and peer review Not commissioned; externally peer reviewed.

Data sharing statement The following statement on data ownership was included in the customised reports to all participating trusts for this quality improvement programme: in line with the original memorandum of understanding between POMH-UK and member healthcare organisations (predominantly mental health NHS Trusts), the following statement outlines the agreement regarding ownership of the audit data in this quality improvement programme. Ownership of the local data submitted to POMH-UK is retained by the healthcare organisation that submitted them. These data have been made available to POMH-UK in a way that is anonymous, with the exception of the identity of the source organisation. The aggregate data from all participating organisations have been analysed by POMH-UK, to produce this customised report. This report summarises the national results and local results at organisation and clinical team levels, benchmarked anonymously against the other organisations taking part. There is a publication strategy allowing POMH-UK to publish the anonymous aggregated data on its website and/or in appropriate scientific journals. Any requests from other organisations for these audit data will be referred to the POMH-UK reports appearing in the public domain or provided with a list of member healthcare organisations and asked to approach them individually. It is each organisation's decision whether, and with whom, to share their data. Reflection by clinical teams on their benchmarked performance is perhaps the most potent element of POMHUK programmes. In addition to performance against the clinical standards, the audit data include demographic, diagnostic and other relevant clinical information that provide a context for interpretation and understanding of practice, which can inform local strategies and systems to achieve improvement. The data collected are designed to be suitable for this clinical purpose, and not for objective ranking of healthcare organisations, for which they are untested and would not necessarily be appropriate.

Open Access This is an Open Access article distributed in accordance with the Creative Commons Attribution Non Commercial (CC BY-NC 4.0) license, which permits others to distribute, remix, adapt, build upon this work non-commercially, and license their derivative works on different terms, provided the original work is properly cited and the use is non-commercial. See: http://creativecommons.org/ licenses/by-nc/4.0/ (c) Article author(s) (or their employer(s) unless otherwise stated in the text of the article) 2018. All rights reserved. No commercial use is permitted unless otherwise expressly granted.

\section{REFERENCES}

1. National Institute for Health and Care Excellence. Bipolar disorder: assessment and management. CG185. 2014 https://www.nice.org.u $\mathrm{k} /$ guidance/cg185?unlid=10051896022016726214857.

2. Cipriani A, Barbui C, Salanti G, et al. Comparative efficacy and acceptability of antimanic drugs in acute mania: a multipletreatments meta-analysis. Lancet 2011;378:1306-15.

3. Goodwin GM, Haddad PM, Ferrier IN, et al. Evidencebased guidelines for treating bipolar disorder: revised third edition recommendations from the British Association for Psychopharmacology. J Psychopharmacol 2016;30:495-553.

4. Smith LA, Cornelius VR, Azorin JM, et al. Valproate for the treatment of acute bipolar depression: systematic review and meta-analysis. $J$ Affect Disord 2010;122:1-9.

5. Robert E, Guibaud P. Maternal valproic acid and congenital neural tube defects. Lancet 1982;2:937.

6. Tomson T, Battino D, Bonizzoni E, et al. Dose-dependent risk of malformations with antiepileptic drugs: an analysis of data from the EURAP epilepsy and pregnancy registry. Lancet Neurol 2011;10:609-17.

7. Campbell E, Kennedy F, Russell A, et al. Malformation risks of antiepileptic drug monotherapies in pregnancy: updated results from the UK and Ireland Epilepsy and Pregnancy Registers. J Neurol Neurosurg Psychiatry 2014;85:1029-34.

8. Tomson T, Battino D. Teratogenic effects of antiepileptic drugs. Lancet Neurol 2012;11:803-13.

9. Meador KJ, Baker GA, Browning N, et al. Cognitive function at 3 years of age after fetal exposure to antiepileptic drugs. N Engl J Med 2009;360:1597-605.

10. Christensen J, Grønborg TK, Sørensen MJ, et al. Prenatal valproate exposure and risk of autism spectrum disorders and childhood autism. JAMA 2013;309:1696-703.

11. Report from Agence Nationale de Sécurité du Médicament and Caisse Nationale de l'Assurance Maladie des Travailleurs Salariés. Exposition in utero à l'acide valprö̈que et aux autres traitements de l'épilepsie et des troubles bipolaires et risque de malformations congénitales majeures (MCM) en France. France: Agence Nationale de Sécurité du Médicament and Caisse Nationale de l'Assurance Maladie des Travailleurs Salariés, 2017.

12. Agency EM. PRAC recommends strengthening the restrictions on the use of valproate in women and girls. 2014. EMA/612389/2014 http:// www.ema.europa.eu/docs/en_GB/document_library/Press_release/ 2014/10/WC500175208.pdf

13. Casassus B. France bans sodium valproate use in case of pregnancy. Lancet 2017;390:217.

14. National Institute for Clinical Excellence (NICE). Newer drugs for epilepsy in adults. Technology Appraisal 76. 2004 https://www.nice. org.uk/guidance/ta76

15. James L, Barnes TR, Lelliott P, et al. Informing patients of the teratogenic potential of mood stabilizing drugs: a case note review of the practice of psychiatrists. J Psychopharmacol 2007;21:815-9.

16. Wieck $A$, Rao $S$, Sein $K$, et al. A survey of antiepileptic prescribing to women of childbearing potential in psychiatry. Arch Womens Ment Health 2007;10:83-5.

17. Mace S, Taylor D. Improving adherence to NICE guidance for bipolar illness: valproate use in women of childbearing potential. Psychiatrist 2011;35:63-7.

18. Atturu $\mathrm{H}$, Odelola $\mathrm{A}$. Valproate Prescribing in Women of Childbearing Age: An Audit of Clinical Practice. Advances in Psychiatry 2015;2015:1-6.

19. Medicines and Healthcare products Regulatory Agency. Toolkit on the risks of valproate medicines in female patients. $2016 \mathrm{https} / / /$ www.gov.uk/government/publications/toolkit-on-the-risks-ofvalproate-medicines-in-female-patients (accessed Aug 2016)

20. Medicines and Healthcare products Regulatory Agency and NHS Improvement. Resources to support the safety of girls and women who are being treated with valproate. London: Medicines and Healthcare products Regulatory Agency and NHS Improvement. Patient Safety Alert, NHS/PSA/RE/2017/002, 6 th April 2017. 